\title{
Revista Catôlicica A IMPORTÂNCIA DO DIAGNÓSTICO PRECOCE DA
TRICOMONÍASE E AS PRINCIPAIS TÉCNICAS UTILIZADAS
NA CONFIRMAÇÃO DA DOENÇA
}

Monaiza de Oliveira Lima Mariana Gomes Vidal Sampaio Bruno Souza dos Santos

\section{RESUMO}

A tricomoníase é uma doença causada pelo protozoário flagelado Trichomonas vaginalis tendo como habitats a vagina da mulher e próstata e uretra do homem. O exame de Papanicolau é um bom método para diagnóstico de tricomoníase, além de seu custo benefício ser baixo, porém o padrão ouro para detectar o parasita Trichomonas vaginalis é a cultura. O objetivo do presente trabalho é realizar uma revisão de literatura sobre a importância do diagnóstico precoce da tricomoníse e as principais técnicas utilizadas na confirmação da doença. As referências para a pesquisa foram extraídas das bases de dados como: PubMed, SciELO e Google Acadêmico, onde foram pesquisados artigos nacionais e internacionais utilizando como descritores: Trichomonas vaginalis, diagnóstico e Infecções Sexualmente Transmissíveis. Foram selecionados 30 artigos para a realização da revisão. Por ser uma doença na maioria das vezes assintomática, é importante a realização de exames para a detecção da doença, para que de fato seja diagnosticado ou não a presença do parasita. Mediante isto, o diagnóstico desta patologia é de crucial importância para que as mulheres infectadas possam receber o tratamento adequado, diminuindo as chances de gerar consequências maiores à saúde das mesmas. Portanto os órgãos públicos de saúde devem investir nos exames mais específicos e sensíveis para o diagnóstico da doença e incentivar a implantação de campanhas que elucidem sobre os agravos atrelados à patologia, proporcionando uma diminuição dos riscos à saúde da população.

DESCRITORES: Trichomonas vaginalis. Doenças Sexualmente Transmissíveis. Diagnóstico.

\section{THE IMPORTANCE OF EARLY DIAGNOSIS OF TRICHOMONIASIS AND THE MAIN TECHNIQUES USED FOR DETECTION OF THE DISEASE}

\begin{abstract}
Trichomoniasis is a disease caused by the flagellated protozoan Trichomonas vaginalis which resides in the woman's vagina and the man's prostate and urethra. The Pap smear is a good method to diagnose trichomoniasis, and its cost benefit is low, but the gold standard for detecting the parasite Trichomonas vaginalis is culturally known. The aim of this work is to develop a systematic review on the importance of early diagnosis of trichomoniasis and the main techniques used to confirm the disease. The references for the research were obtained from databases such as: PubMed, SciELO and Google Scholar, where national and international papers were searched using as descriptors: Trichomonas vaginalis, diagnosis and Sexually Transmitted Infections. 30 papers were selected for the review. Because it is often an asymptomatic disease, it is important to perform tests to detect the disease, so that the parasite presence can be actually diagnosed. Therefore, the diagnosis of this pathology is of decisive value for infected women to receive the appropriate treatment, reducing the chances of generating greater consequences for their health. In conclusion, public health agencies should invest in more specific and sensitive tests for the diagnosis of such disease and encourage campaigns in order to prevent severe effects related to this pathology, thus reducing health risk factors in the population.
\end{abstract}

Enviado em: 03/05/2018

Aceito em: 05/06/2018 Publicado em: 21/06/2018

DESCRIPTORS: Trichomonas vaginalis. Sexually Transmitted Diseases. Diagnosis. 


\section{INTRODUÇÃO}

A tricomoníase é uma doença causada pelo protozoário flagelado Trichomonas vaginalis tendo como habitats a vagina da mulher e próstata e uretra do homem. Quando sintomático na mulher, manifesta corrimento esbranquiçado, em decorrência da leucorréia, podendo ser bolhoso e de odor fétido. Cervicite, vulvovaginite e prurido intenso podem ser observados. No caso dos homens, a maioria é assintomático, quando sintomáticos manifestam uretrites, prurido e secreção purulenta pela manhã (REY, 2001).

Esse parasita se apresenta normalmente com morfologia ovóide, provido de quatro flagelos anteriores livres e um entre a membrana ondulante, que permite a motilidade do protozoário. Diferente de outras infecções sexualmente transmissíveis, a tricomoníase afeta mais mulheres com faixa etária entre 40-50 anos (BRASIL, 2015).

Alterações na flora vaginal ocasionadas pelo período pré-menstrual e duchas, podem levar à alcalinização da vagina, promovendo um desequilíbrio da flora bacteriana normal, deixando a pessoa susceptível a desenvolver doenças. $\mathrm{O}$ correto é que o $\mathrm{pH}$ vaginal seja ácido, em decorrência da presença dos lactobacilos, produtores de ácido lático (SOPER, 1998).

A profilaxia da tricomoníase é a mesma de outras Infecções Sexualmente Transmissíveis (IST) não virais. Deve-se ter um controle adequado através da triagem e posterior tratamento das mulheres e seus parceiros sexuais, favorecendo o controle da infecção. Outra ação importante é a criação de medidas educativas que visem erradicar esta doença (SANTOS, 2011).

O exame de Papanicolau é um bom método para diagnóstico de tricomoníase, além de possuir baixo custo benefício. É utilizado para identificar lesões precursoras do câncer uterino como também para identificar IST, porém o padrão ouro para detectar o parasita Trichomonas vaginalis é a cultura (COUTO, 2015; FERRAZ et al., 2014).

Como a tricomoníase pertence ao grupo de doenças causadoras de IST, podendo levar a manifestações clínicas graves principalmente nas mulheres, objetivou-se realizar uma revisão de literatura sobre a importância do diagnóstico precoce da tricomoníase e as principais técnicas utilizadas na confirmação da doença.

\section{MÉTODO}

Estudo do tipo revisão de literatura, realizado nas bases de dados: PubMed e SciELO, utilizando os seguintes descritores: Trichomonas vaginalis, Diagnóstico e Infecções Sexualmente Transmissíveis. $O$ período de busca dos artigos ocorreu entre os meses de março a junho de 2017.

Os critérios de inclusão foram: artigos publicados em português e inglês, disponíveis gratuitamente na íntegra, datados entre os anos de 1994 a 2016, e que abordassem a importância do diagnóstico precoce da tricomoníase e as principais técnicas utilizadas. Os critérios de exclusão foram: artigos que não contemplassem o assunto abordado, artigos incompletos e repetidos.

Inicialmente foram selecionados 63 artigos a partir da leitura dos títulos e resumos, destes apenas 30 artigos se enquadraram nos critérios de inclusão, desta forma foi realizada a leitura por completo deles, com subsequente extração dos dados para responder os questionamentos do estudo.

\section{RESULTADOS E DISCUSSÃO}

O protozoário $T$. vaginalis, possui flagelos que permitem a sua mobilidade. Trata-se de um parasita de transmissão sexual, causador de vaginite e cervicite no sexo feminino, com aparecimento de corrimento vaginal, prurido, ardência e queimação principalmente durante a relação sexual e a noite. No entanto esses sinais só aparecem nos casos sintomáticos, sendo a maioria das mulheres portadoras assintomáticas (REY, 2013).

A tricomoníase é a Infecção Sexualmente Transmissível não viral mais comum em todo o mundo, podendo ser assintomática em alguns casos e, em outros pode levar à neoplasia cervical (MACIEL; TASCA; CARLI, 2004).

\subsection{TRICHOMONAS VAGINALIS}

O parasita é constituído morfologicamente por uma membrana ondulante nas costas, flagelos com estrutura diferente, possuem ainda núcleo elipsóide e axóstilo. A ausência de mitocôndria é compensada pela presença dos hidrogenossomos, observados na microscopia. Quando vivos possuem forma esférica, oval ou elipsoide, essas formas variam de acordo com o ambiente físico-químico em que o parasita se encontra (CARLI; TASCA, 2005; REY, 2013).

No sexo masculino a tricomoníase é assintomática em quase todos os casos, nas mulheres a porcentagem de sintomáticos é um pouco maior quando comparado aos homens. Portanto, o diagnóstico laboratorial é de grande importância para detectar os casos da doença nos assintomáticos e nos sintomáticos, já que os sinais e sintomas são semelhantes a outras infecções genitais. A cultura de secreção e a reação em cadeia da polimerase (PCR) são os métodos mais confiáveis a serem utilizados (MACHADO; SOUZA, 2012).

A tricomoníase é um dos agentes causadores da cervicite, podendo evoluir para um processo inflamatório pélvico. Em outros países a notificação de casos de tricomoníase é obrigatória, enquanto no Brasil não se trata de doença de notificação compulsória (PESSOA et al., 2012).

Existem três formas de transmissão do parasita T. vaginalis, por relação sexual desprotegida, durante o parto (transmissão vertical) e fômites. O período de incubação é entre 4 e 20 dias após o indivíduo ser infectado (FERRACIN; OLIVEIRA, 2005; SANTOS, 2008).

Distingue-se objetos de uso pessoal como fômites, a infecção por esse meio é rara, mas pode acontecer, assim como uso de vaso sanitário e duchas de banho. Essa colonização dos fômites, que são objetos inanimados, ocorre pelo contato de secreções ou 
qualquer outro material biológico que contenha o microrganismo, ele vai sobreviver por algum tempo até encontrar um novo hospedeiro e se instalar (VALE; DINIS, 2011).

\subsection{MANIFESTAÇÕES CLÍNICAS}

Os homens na grande maioria são portadores assintomáticos deste parasita. Quando sintomáticos podem manifestar disúria, corrimento uretral de aspecto purulento, infecção do epidídimo e próstata e dor testicular (COUTO, 2015). Nas mulheres o odor fétido e dispareunia são relatados em alguns casos, podendo ocasionar cervicite, uretrite, secreção purulenta, espumosa, amarelo esverdeada, prurido, disúria, colpitis macularis ou colo em morango (DOMEIKA et al., 2010; LIMA et al., 2013; PESSOA et al., 2012).

Um estudo realizado com 742 mulheres demonstrou que 332 estavam com a tricomoníase e os sintomas mais relatados foram: prurido na região uretral, corrimento amarelado ou embranquecido, em alguns casos fétidos, além de ardência (GRAMA, 2011).

Casos sem tratamento ou infecções recorrentes, levam a quadros de prostatites, câncer uretral ou prostático nos homens, infertilidade e até mesmo parto prematuro nas mulheres (MACHADO; SOUZA, 2012).

\subsection{METODOLOGIAS DE DIAGNÓSTICO}

Por ser uma doença na maioria das vezes assintomática, é importante a realização de exames para a detecção da doença, para que de fato seja diagnosticado ou não a presença do parasita. Os exames mais indicados nesses casos são as técnicas de PCR e cultura de secreção vaginal (MACHADO; SOUZA, 2012).

\subsubsection{Cultura de secreção vaginal}

A cultura de secreção vaginal ainda é o padrãoouro para detectar tricomoníase. As limitações desse método são o tempo de crescimento do parasita na cultura Diamond que pode levar até 7 dias, além do custo um pouco maior quando comparado a outros testes (FERRAZ et al., 2014).

A limitação desse método é custo mais caro, desta forma acaba muitas vezes não sendo aplicado na rotina laboratorial. Outro problema é a contaminação da cultura por bactérias da flora vaginal feminina, mesmo adicionando antibiótico ao meio essas bactérias acabam crescendo, impossibilitando as vezes a visualização do parasita ou até mesmo o seu crescimento (GRAMA, 2011).

\subsubsection{Papanicolau e colposcopia}

O teste de Papanicolau detecta lesões precursoras do câncer uterino, este é o intuito deste exame, porém estados de inflamação e infecção também podem ser identificados. A citologia uterina é realizada como exame preventivo, detectando precocemente o câncer do colo do útero (FREITAS FILHO, 2011).

Os profissionais da saúde qualificados podem fazer a coleta do material citológico. Cabe a eles o papel de acolher bem essas mulheres, para que cada vez mais se tornem adeptas aos exames ginecológicos preventivos, extinguindo qualquer receio que as mesmas possam vir a apresentar em relação a este exame (JORGE et al., 2011).

A principal ação que estimula a aderência dessas mulheres a fazer esse teste é a atividade educativa, sendo bastante aceita pelas mesmas. Tratase de uma ação de baixo custo e pode ser realizado na atenção primária de saúde, em domicílio, e em qualquer lugar, todo profissional de saúde pode trabalhar nesta intervenção (SOARES; SILVA, 2016).

No ano de 1988 o Ministério da Saúde juntamente com outras instituições internacionais e o Instituto Nacional do Câncer, instituíram que no Brasil o exame citopatológico deve ser realizado por mulheres com faixa etária de 25 aos 64 anos de idade, e também as que já possuem vida sexual ativa, deve ser feita uma vez por ano, ou a cada 3 anos, caso a citologia anual seja negativa duas vezes seguidas (INCA, 2002).

A colposcopia é uma técnica que deve ser feita por médicos habilitados, emprega-se o uso de um aparelho com luz e lentes de aumento. Utiliza-se bastante essa técnica para orientar o local onde será feito a biópsia, servindo também para avaliar a extensão da lesão no colo uterino, assim como em processos inflamatórios intensos. Portanto esse método será empregado quando a citologia não for clara, com isso a colposcopia irá orientar o estudo histopatológico e biópsia (MELLO, 2014).

Uma entrevista feita com gestantes atendidas no Programa Saúde da Família de Guarani D'Oeste mostrou grande aceitação para a realização do exame de papanicolau durante a gestação. Isso evidencia a importância da promoção de saúde, realizada pelos profissionais para incentivar essa prática (YASSOYAMA; SALOMÃO; VICENTINI, 2005).

O exame de Papanicolau é um dos exames realizados pelas gestantes durante o pré-natal, em detrimento disto, torna-se importante aproveitar esse acompanhamento médico da gestante para se realizar o exame preventivo (SANTANA; SANTOS; MACHADO, 2013).

O material para análise é colhido da região da ectocérvice e endocérvice, no caso de mulheres não gestantes, essas células são colocadas em lâmina de vidro, coradas e analisadas ao microscópio, onde o profissional habilitado irá distinguir as células normais, pré-malignas e malignas, caso exista alguma anormalidade (FREITAS FILHO, 2011).

\subsubsection{Exame de urina}

$\mathrm{Na}$ análise do sedimento urinário é possível identificar o protozoário, no entanto a sua visualização é dificultosa, pois pode ser confundido com outras estruturas. Esse método não é o de escolha para diagnóstico, mas eventualmente pode ser visualizado em um exame de urina (RAVEL, 1997).

\subsubsection{Diagnóstico molecular}

Lima, Sampaio e Santos 
A reação em cadeia da polimerase (PCR) é uma técnica molecular, que pode ser usada para 0 diagnóstico da tricomoníase, sendo mais rápida que a cultura de secreção, que pode levar até 7 dias para 0 crescimento do protozoário (JEREMIAS et al., 1994).

Atualmente o melhor teste para detectar o parasita $T$. vaginalis é o PCR em tempo real, várias amostras podem ser utilizadas para o exame como: secreção vaginal no caso das mulheres e secreção uretral no caso dos homens, urina e a amostra usada na colposcopia (TORRES FILHO; LEITE, 2015).

\subsection{TRATAMENTO E PROFILAXIA}

O medicamento mais amplamente utilizado para o tratamento desta doença é o metronidazol, deve ser ingerido por via oral, duas vezes ao dia, por sete dias, mas o seu uso em dose única vem sendo uma escolha, já que muitos acabam não seguindo corretamente o tratamento, interrompendo-o antes dos sete dias. 0 secnidazol e tinidazol também podem ser utilizados (BRAVO et al., 2010). A prevenção é uma forma de controlar esta enfermidade, a proteção durante as relações sexuais minimiza as probabilidades de se adquirir o parasita (VASCONCELOS et al., 2016).

A mulher e seu parceiro devem ser tratados simultaneamente, para que não ocorra reinfeção. Para a prevenção contra essa doença recomenda-se a utilização de preservativos durantes as relações sexuais, diminuir a quantidade de parceiros sexuais, tomar cuidado com o uso de fômites, evitar o uso dos mesmos ou esteriliza-los (HOBBS et al., 2006).

\section{CONCLUSÕES}

A tricomoníase, doença que apresenta maior gravidade no sexo feminino, levando ao desenvolvimento de vulvovaginite, cervicite, entre outras manifestações clínicas, pode ser ainda mais grave em gestantes e ocasionar parto prematuro, ruptura da placenta e aborto.

Diante disto, o diagnóstico desta patologia é de crucial importância para que as mulheres infectadas possam receber o tratamento adequado, diminuindo as chances de gerar consequências maiores à saúde das mesmas. Portanto os órgãos públicos de saúde devem investir nos exames mais específicos e sensíveis para o diagnóstico da doença e incentivar a implantação de campanhas que elucidem sobre os agravos atrelados à patologia, proporcionando uma diminuição dos riscos à saúde da população.

\section{REFERÊNCIAS}

BRASIL. Ministério da Saúde. Secretaria de Vigilância em Saúde. Diagnóstico laboratorial de doenças sexualmente transmissíveis, incluindo o vírus da imunodeficiência humana. Organização Mundial da Saúde, 2015.

BRAVO, R. S. et al. Tricomoníase vaginal: o que se passa?. DST- Jornal Brasileiro de Doenças
Sexualmente Transmissíveis, Rio de Janeiro, v. 22, n. 2, p. 73-80, 2010.

CARLI, G. A; TASCA, T. Trichomonas. In: NEVES, D. P. Parasitologia Humana. São Paulo: Atheneu, 2005. p. 115-120.

COUTO, V. L. Epidemiologia da Tricomoníase na população humana masculina e feminina, do município de Teixeira, Paraíba/ Brasil. 2015. Monografia (Licenciatura em Ciências Biológicas) Unidade Acadêmica de Ciências Biológicas,

Universidade Federal de Campina Grande, Patos, 2015.

DOMEIKA, M. et al. Guidelines for the laboratory diagnosis of trichomoniasis

in East European countries. Journal of the European Academy of Dermatology and Venereology, Malden, v. $24, \mathrm{n} 10$, p. 1125-1134, 2010.

FERRACIN, I.; OLIVEIRA, R. M. W. Corrimento vaginal: causa, diagnóstico e tratamento farmacológico. Infarma - Ciências farmacêuticas, Brasília, v. 17, n. 5/6, p. 8286. 2005.

FERRAZ, R. R. et al. Métodos de diagnóstico da tricomoníase: comparação do método da microscopia de montagem molhada com o método de cultura convencional. Saúde em Foco, Rio de Janeiro, v. 3, n. 1, p. 40-43, 2014.

TORRES FILHO, H. M.; LEITE, C. C. F. Doenças sexualmente transmissíveis curáveis-Diagnóstico laboratorial. Jornal Brasileiro de Medicina, Rio de Janeiro, v. 103, n. 1, p. 17-24, mar. 2015.

FREITAS FILHO, L. A. O exame de papanicolau e o diagnóstico das lesões invasoras do colo de útero. 2011. Monografia (Especialista em Citologia Clínica) Centro de consultoria educacional, Universidade Paulista, Recife, 2011.

GRAMA, D. F. Prevalência e fatores de risco para Trichomonas vaginalis em mulheres atendidas em unidades de saúde pública no município de Uberlândia-MG e comparação entre técnicas de diagnóstico. 2011. Dissertação (Mestre em Imunologia e Parasitologia Aplicada) - Instituto de Ciências Biomédicas, Universidade Federal de Uberlândia, Minas Gerais, 2011.

HOBBS, M. M. et al. Methods for detection of Trichomonas vaginalis in the male partners of infected women: implications for control of trichomoniasis. Journal of Clinical Microbiology, Washington, v. 44, n. 11, p. 3994-3999, nov. 2006.

INCA, INSTITUTO NACIONAL DO CÂNCER. Prevenção e controle do câncer. Revista Brasileira de Cancerologia, v. 48, n. 3, p. 317-332, 2002.

JEREMIAS, J. et al. Detection of Trichomonas vaginalis using the polymerase chain reaction in pregnant and 
non-pregnant women. Infectious Diseases in Obstetrics and Gynecology, London, v. 2, n. 1, p. 1619, 1994.

JORGE, R. J. B. et al. Exame Papanicolau: sentimentos relatados por profissionais de enfermagem ao se submeterem a esse exame. Ciência \& Saúde Coletiva, Rio de Janeiro, v. 16, n. 5, p. 2443-2451, 2011.

LIMA, M. C. L. et al. Prevalência e fatores de risco independentes à tricomoníase em mulheres assistidas na atenção básica. Acta Paulista de Enfermagem, São Paulo, v. 26, n. 4, p. 331-337, 2013.

MACHADO, E. R; SOUZA, L. P; Tricomoníase: Assistência de enfermagem na prevenção e controle. Ensaios e ciência: Ciências biológicas, agrárias e da saúde, São Paulo, v. 16, n. 4, p. 229-243, 2012.

MACIEL, G. P; TASCA, T; CARLI, G. A. Aspectos clínicos, patogênese e diagnóstico de Trihomonas vaginallis. Jornal brasileiro de patologia e medicina laboratorial, Rio de Janeiro, v. 40, n. 3, p. 152-160, junho-2004.

MELLO, I. M. COLPOSCOPIA. In: MARTINS, N. V. Patologia do trato genital inferior: diagnóstico e tratamento. Rio de Janeiro: ROCA, 2014.

PESSOA, D. C. et al. Trichomonas vaginalis: como agente casual de cérvico - colpite. Infarma - Ciências farmacêuticas, Brasília, v. 24, n. 1-3, p. 124-131, 2012.

RAVEL, R. Laboratório clínico. Aplicações clínicas dos dados laboratoriais. 6. ed. Rio de Janeiro: Guanabara Koogan, 1997.

REY, L. Bases da parasitologia médica. 3. ed. Rio de Janeiro: Guanabara Koogan, 2013.

REY, L. Parasitologia. 3. ed. Rio de Janeiro: Guanabara Koogan, 2001.

SANTANA, J. E. O.; SANTOS, M.; MACHADO, I. L. D. A importância da realização do Papanicolau em gestantes: uma revisão de literatura. Cadernos de Graduação - Ciências Biológicas e da Saúde, Aracajú, v. 1, n. 17, p. 39-48, out. 2013.

SANTOS, A. V. A. Reações de óxido redução como alvo na quimioterapia triconomicida. 2008. Dissertação (Mestrado em Biotecnologia e Saúde e Medicina Investigativa) - Fundação Oswaldo Cruz: Centro de pesquisa Gonçalo Moniz, Salvador, 2008.

\section{SANTOS, M. R. C. L. Estudo do Trichomonas} vaginalis e sua abordagem no diagnóstico citológico. 2011. Monografia (Especialização em Citologia Clínica) - Centro de consultoria educacional, Universidade Paulista, Recife, 2011.

SOARES, M. B. O.; SILVA, S. R. Interventions that facilitate adherence to Pap smear exam: integrative review. Revista Brasileira de Enfermagem, Brasília, v. 69, n. 2, p. 404-414, mar./abr. 2016.

SOPER, D. E. Infecções geniturinárias e doenças sexualmente transmitidas. In: BEREK, J. S., ADASHI, E. Y., HILLARD, P.A. Tratado de Ginecologia. Rio de Janeiro: Guanabara Koogan, 1998.

VALE, B.; DINIS, A. O papel das fomites na transmissão de doenças infeciosas. Revista Saúde Infantil, Coimbra, v. 33, n. 1, p. 23-27, abr. 2011.

VASCONCELOS, C. N. E. et al. Estudo comparativo entre terapia oral e local no tratamento de corrimento vaginais: candidíase, tricomoníase e vaginose bacteriana. Brazilian Journal of Surgery and Clinical Research, Maringá, v. 15, n. 1, p. 123-128, jun./ago. 2016.

YASSOYAMA, M. C. B. M.; SALOMÃO, M. L. M.; VICENTINI, M. E. Características das mulheres que realizam exame preventivo do colo do útero durante a gestação: bases para estratégias do programa de saúde da família (PSF). Revista Arquivos de Ciências da Saúde, São Paulo, v. 12, n. 4, p. 172-176, out./dez. 2005.

\section{SOBRE OS AUTORES}

\section{Monaiza de Oliveira Lima \\ Centro Universitário Doutor Leão Sampaio, Brasil}

Graduada em biomedicina pela UNILEÃO.

E-mail: monaizaoliveira4@gmail.com

Mariana Gomes Vidal Sampaio

Centro Universitário Católica de Quixadá, Brasil

Doutoranda em Ciências Biológicas pela UFPE.

E-mail: marianavidalsampaio@gmail.com

\section{Bruno Souza dos Santos \\ Universidade Federal de Pernambuco, Brasil}

Doutor em Bioquímica e Fisiologia pela Universidade Federal de Pernambuco, UFPE (2018). Mestrado em Biotecnologia Industrial pela Universidade Federal de Pernambuco, UFPE (2014). Graduação em Farmácia pela Universidade Federal de Pernambuco, UFPE (2010).

E-mail: souza.farmacia@hotmail.com 